\title{
RESEARCH ON THE CONFLICT OF DUAL GOALS OF MICROFINANCE INSTITUTIONS-TAKING CHINA AS AN EXAMPLE
}

\author{
Yiru Wang \\ Nanjing University of Aeronautics and Astronautics, Nanjing, China. \\ DOI: 10.46609/IJSSER.2020.v05i02.013 URL: https://doi.org/10.46609/IJSSER.2020.v05i02.013
}

\begin{abstract}
Microfinance institutions have two goals: social poverty alleviation goals and business sustainable development goals. However, at this stage, the dual goals of microfinance institutions in many countries are difficult to coordinate and restrict the construction and development of the inclusive financial system. This paper uses Chinese data as an example to conduct theoretical analysis and empirical test on the inherent conflict between dual goals; Theoretical analysis shows that despite the conflict of dual goals, there is also the possibility of balance and coordination; The empirical test is based on the data of 172 sample microfinance institutions from 2013 to 2018, and constructs a simultaneous equation model for regression analysis. The conclusion indicates that there is a negative correlation between the dual goals of microfinance institutions. At the same time, the influencing factors of the dual goals are analyzed, and corresponding policy recommendations are proposed to promote the coordinated development of the dual goals.
\end{abstract}

Keywords: Microfinance institutions, Dual goals, Conflict, Simultaneous equation model, Policy recommendations

\section{INTRODUCTION}

The purpose of microfinance is to help low-income people obtain financial services. Microfinance institutions, as operators of microfinance, have an important role in helping the poor, and an important force for the country to promote the construction of an inclusive financial system $^{[1]}$. Microfinance institutions have dual goals. On the one hand, they must respond to the state's call, fulfill their social responsibilities, firmly serve the market positioning of the poor and promote the goal of inclusive financial development, and on the other hand, they must maintain the sustainability of their own business development ${ }^{[2]}$. However, in actual operation, some 
International Journal of Social Science and Economic Research

ISSN: $2455-8834$

Volume: 05, Issue: 02 "February 2020"

micro-financial institutions are facing difficulties in maintaining their sustainable development, or organizations that have implemented commercial operations have turned their target customer groups to richer people, and they have experienced a "mission drift" phenomenon ${ }^{[3][4]}$. It is difficult to coordinate the development of social poverty alleviation goals and business sustainable development goals. Analyzing the conflict between the dual goals and promoting the coordinated development of the dual goals is very important for the construction of inclusive finance and the improvement of people's livelihood. It is an urgent problem in the field of microfinance. This paper takes China as an example to study the conflict between the dual goals of microfinance institutions at the current stage from the theoretical and empirical perspectives, analyzes the possibility and influencing factors of microfinance institutions to achieve dualobjective equilibrium, and proposes policy recommendations to promote the coordinated development of dual-objectives.

\section{THE INHERENT CONFLICT OF DUAL GOALS — MATHEMATICAL MODEL ANALYSIS}

\subsection{Short-term model analysis}

In theory, if microfinance institutions provide small and low-interest loans to customer groups below the poverty line, compared to traditional credit, they will have to bear higher transaction and operating costs. With greater credit risk, in order to improve the efficiency of financial operations, it is difficult to avoid sacrificing the efficiency of social services. Due to the nature of profit-seeking capital, the relative balance between dual goals is easily broken, and there is an inherent conflict between the two.

In the short term, this paper assumes that the funds held by MFIs at this stage are M. All of its capital is used to issue loans, some of which serve poor customer groups, with a ratio of a, interest rate of $r_{1}$, and loan loss rate of $\mathrm{p}_{1}$; the other part of which serve rich customer groups, with a ratio of 1-a, interest rate of $r_{2}$, and loan loss rate of $p_{2} . r_{1}>r_{2}, p_{1}>p_{2}$. We assume that microfinance institutions can specify different $r_{1}$ in the short term. We assume that the cost of microfinance institutions serving poor customer groups is $\mathrm{W}_{1}+\mathrm{b}^{*} \mathrm{aM}$, which means that the cost increases with the increase of credit funds issued; The affluent customer market is relatively mature and has a stable cost of capital ratio. It is represented by $\mathrm{W}_{2}, \mathrm{~W}_{1}>\mathrm{W}_{2}$. The profit obtained from issuing loans to affluent customer groups is greater than 0 , otherwise microfinance institutions will not issue loans to them, and $M\left[\left(1+r_{2}\right)\left(1-p_{2}\right)-1-W_{2}\right]>0$, and the same applies to poor customer groups. The profit of microfinance institutions is $\mathrm{R}_{\text {net }}=\mathrm{R}_{\text {total }}-\mathrm{W}_{\text {total, }}$ which is subject to the constraints of dual goals: the commercial sustainable development goal constraint: $\mathrm{R}_{\text {net }}>0$; the social poverty reduction goal constraint: $\mathrm{a}>\mathrm{a}^{*}$. The proportion of microfinance institutions that provide financial services to poor customer groups must reach a certain level. 
The profit of microfinance institutions is:

$$
\begin{aligned}
\mathrm{R}_{\mathrm{net}}= & \mathrm{R}_{\text {total }}-\mathrm{W}_{\text {total }}=\mathrm{aM}\left[\left(1+\mathrm{r}_{1}\right)\left(1-\mathrm{p}_{1}\right)-1\right]+(1-\mathrm{a}) \mathrm{M}\left[\left(1+\mathrm{r}_{2}\right)\left(1-\mathrm{p}_{2}\right)-1\right]-\mathrm{aM}\left(\mathrm{W}_{1}+\mathrm{baM}\right)-(1-\mathrm{a}) \mathrm{MW}_{2} \\
& =\mathrm{M}\left\{\mathrm{a}\left[\left(1+\mathrm{r}_{1}\right)\left(1-\mathrm{p}_{1}\right)-1-\mathrm{W}_{1}-\left(1+\mathrm{r}_{2}\right)\left(1-\mathrm{p}_{2}\right)+1+\mathrm{W}_{2}\right]-\mathrm{ba}^{2} \mathrm{M}+\left(1+\mathrm{r}_{2}\right)\left(1-\mathrm{p}_{2}\right)-1-\mathrm{W}_{2}\right\}
\end{aligned}
$$

$r_{\text {net }}=a\left[\left(1+r_{1}\right)\left(1-p_{1}\right)-W_{1}-\left(1+r_{2}\right)\left(1-p_{2}\right)+W_{2}\right]-b^{2} M+\left(1+r_{2}\right)\left(1-p_{2}\right)-1-W_{2}$ represents profit margin. $R_{\text {net }}>0, M>0$, so $r_{n e t}>0$. $r_{n e t}$ is a quadratic function about a. Because $M\left[\left(1+r_{2}\right)\left(1-p_{2}\right)-1-W_{2}\right]>0$, $M>0$, we can know that $\left(1+r_{2}\right)\left(1-p_{2}\right)-1-W_{2}>0$. When $a=0, r_{n e t}=\left(1+r_{2}\right)\left(1-p_{2}\right)-1-W_{2}>0$, so the curve of $r_{n e t}$ with respect to a is shown in Figure 1.

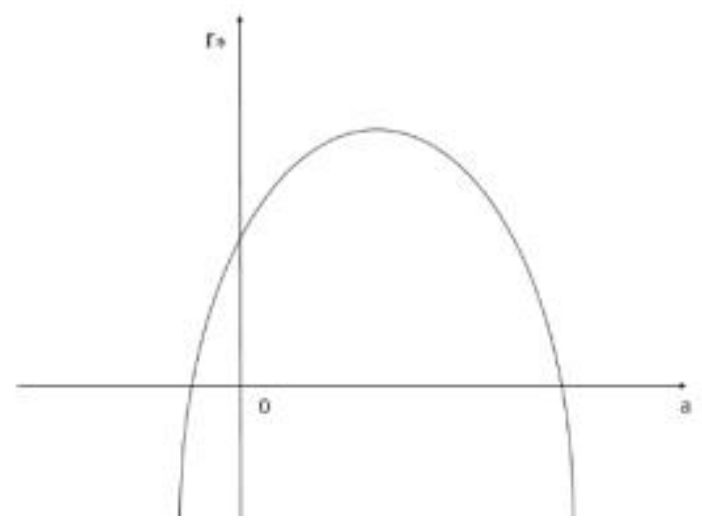

Fig. 1: The curve of $\mathbf{r}_{\text {net }}$ with respect to a

The $r_{n e t}$ achieves the maximum value at the vertex of the quadratic function, which means that the profit of the corresponding microfinance institution achieves the maximum value, and at this time, the commercial sustainable development goal is achieved. Solving the quadratic function gives:

$$
\mathrm{a}^{\prime}=\frac{\left[\left(1+\mathrm{r}_{1}\right)\left(1-\mathrm{p}_{1}\right)-\mathrm{W}_{1}-\left(1+\mathrm{r}_{2}\right)\left(1-\mathrm{p}_{2}\right)+\mathrm{W}_{2}\right]}{2 \mathrm{bM}}
$$

Based on the above derivation, the relationship between $\mathrm{a}^{\prime}$ and $\mathrm{r}_{1}$ is obtained. Microfinance institutions can achieve different development strategies by formulating different interest rates for loans to poor customer groups. Therefore, the realization of their dual goals is different. As there is currently no precise quantitative indicator to measure the achievement of dual goals, this paper draws 0.5 as a cut-off value to describe the realization of dual goals of microfinance institutions. 
International Journal of Social Science and Economic Research

ISSN: $2455-8834$

Volume: 05, Issue: 02 "February 2020"

Let $\mathrm{a}^{\prime}=\left[\left(1+\mathrm{r}_{1}\right)\left(1-\mathrm{p}_{1}\right)-\mathrm{W}_{1}-\left(1+\mathrm{r}_{2}\right)\left(1-\mathrm{p}_{2}\right)+\mathrm{W}_{2}\right] / 2 \mathrm{bM}=0.5$, and solve for $\mathrm{r}_{1} *$. If the microfinance institution distributes the resources of the dual objective in a balanced way, then a $'=0.5$, and the corresponding $r_{1}$ is $r_{1}^{*}$. a' is directly proportional to $r_{1}$. When $r_{1}<r_{1}^{*}$, a' is less than 0.5 , and microfinance institutions focus more on business sustainable development goals. When $r_{1}>r_{1} *, a^{\prime}$ is greater than 0.5 , and microfinance institutions are more focused on social poverty reduction goals.

In the short term, in reality, microfinance institutions are more concerned about the sustainable business development goals. When $r_{n e t}$ reaches the maximum value, $r_{n e t}>0$, and when its profit is maximized, $a=a^{\prime}$, the business sustainable development goal of the MFIs is achieved, then only the constraints of the social poverty alleviation goal need to be considered. When $\mathrm{a}^{*}$ is less than 0.5 , the institution sets different interest rates $r_{1}$ to obtain a' which is less than 0.5 , equal to 0.5 , and greater than 0.5 . The institution can adopt commercial sustainable development goal priority strategies, social poverty reduction goal priority strategies, and balanced development strategies; When $a^{*}$ is equal to 0.5 , the institution sets different interest rates $r_{1}$ to get a' which is equal to 0.5 and greater than 0.5 , and the institution can adopt the social poverty reduction target priority strategy and balanced development strategy; When $a^{*}$ is greater than 0.5 , microfinance institutions can formulate different interest rates $\mathrm{r}_{1}$ to obtain a' which is greater than 0.5. Microfinance institutions can only choose the strategy that prioritizes social poverty alleviation.

According to the above results, in the short term, it is difficult for microfinance institutions to achieve

simultaneous development of dual goals, and most of MFIs will focus more on one of them. There is a certain conflict in the dual goals of MFIs, and the tendency to one goal will sacrifice the other to a certain extent.

\subsection{Long-term model analysis}

Under the condition that the market development is gradually mature, the long-term strategy choice of MFIs are different from the short-term ones. In the long term, this paper assumes that the funds held by MFIs at this stage are $\mathrm{M}_{1}$. All of its capital is used to issue loans, some of which serve poor customer groups, with a ratio of a, interest rate of $r_{1}$, and loan loss rate of $\mathrm{p}_{1}$; the other part of which serve rich customer groups, with a ratio of 1-a, interest rate of $r_{2}$, and loan loss rate of $\mathrm{p}_{2} . \mathrm{r}_{1}>\mathrm{r}_{2}, \mathrm{p}_{1}>\mathrm{p}_{2}$. Since the average market interest rate determines the long-term interest rate, it can be assumed that $r_{1}$ and $r_{2}$ are fixed in the long run. This paper uses the average total cost rate to describe the cost of providing financial services to two types of customer groups in the long run. We assume that the average total cost rate for poor customer groups is $\mathrm{W}_{1}$, and the average total cost rate for rich customer groups is $\mathrm{W}_{2}, \mathrm{~W}_{1}>\mathrm{W}_{2}$. In the long run, due to the 
arbitrage of sufficient investment funds in the market, the net profit margins of the two types of customers tend to be unified, $\left(1+\mathrm{r}_{1}\right)\left(1-\mathrm{p}_{1}\right)-1-\mathrm{W}_{1}=\left(1+\mathrm{r}_{2}\right)\left(1-\mathrm{p}_{2}\right)-1-\mathrm{W}_{2}$. We assume that net income $\mathrm{R}_{\text {net }}=\mathrm{R}_{\text {total }}-\mathrm{W}_{\text {total }}$. As in the short-term model analysis above, the ratio a is used to represent the trade-off of the dual objectives of microfinance institutions. In the short-term, the capital scale of the institution will remain basically unchanged; in the long-term, the institution can expand the scale of capital through some financing methods. We assume that the capital of the institution's $t$ period is $\mathrm{M}_{\mathrm{t}}$. The sources of financing for microfinance institutions are commercial investment funds and social investment funds. It is assumed that the financing amount of social investment funds is proportional to the proportion of assets invested by the microfinance institutions in the poor customer groups. The financing of social investment funds in period $t$ is $b_{1} a_{t-1}$; The financing amount of the commercial investment funds is directly proportional to the net profit of the previous institution. The financing amount of the commercial investment funds in the $t$

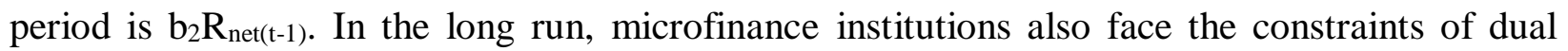
goals: (1) the commercial sustainable development goal constraint: $R_{n e t}>0$; (2) the social poverty alleviation goal constraint: $\mathrm{a}>\mathrm{a}^{*}$, the proportion of microfinance institutions that provide financial services to poor customer groups must reach a certain level.

The single-period profit of the microfinance institution is:

$$
\mathrm{R}_{\mathrm{net}}=\mathrm{R}_{\mathrm{total}}-\mathrm{W}_{\text {total }}=\mathrm{aM}\left[\left(1+\mathrm{r}_{1}\right)\left(1-\mathrm{p}_{1}\right)-1\right]+(1-\mathrm{a}) \mathrm{M}\left[\left(1+\mathrm{r}_{2}\right)\left(1-\mathrm{p}_{2}\right)-1\right]-\mathrm{aMW}_{1}-(1-\mathrm{a}) \mathrm{MW}_{2}
$$

Because $\left(1+r_{1}\right)\left(1-p_{1}\right)-1-W_{1}=\left(1+r_{2}\right)\left(1-p_{2}\right)-1-W_{2}$, we can know that $R_{\text {net }}=R_{\text {total }}-W_{\text {total }}=M^{*} R^{*}$.

The net profit of the t-term microfinance institution is $\mathrm{M}_{\mathrm{t}}{ }^{*} \mathrm{R}^{*}$, and the capital of the t-term microfinance institution is the sum of the previous period's capital and net profit plus the current financing amount:

$$
M_{t}=M_{t-1}+R_{n e t(t-1)}+b_{1} M_{t-1}+b_{2} R_{n e t(t-1)}=M_{1}\left(1+R^{*}+b_{1} a+b_{2} R^{*}\right)^{t-1}
$$

Suppose the microfinance institution has n periods, and the total profit is:

$$
R_{n}=\sum_{i=1}^{n} R_{i}=M_{1} R^{*}+\sum_{i=2}^{n} M_{i-1}\left(1+R^{*}+b_{1} a+b_{2} R^{*}\right) R^{*}=M_{1} R^{*} \sum_{i=1}^{n}\left(1+R^{*}+b_{1} a+b_{2} R^{*}\right)^{i-1}
$$

Since $\mathrm{M}_{1} \mathrm{R}^{*}$ is constant, $1+\mathrm{R}^{*}+\mathrm{b}_{1} \mathrm{a}+\mathrm{b}_{2} \mathrm{R}^{*}>1$,

$\sum_{\mathrm{i}=1}^{\mathrm{n}}\left(1+\mathrm{R}^{*}+\mathrm{b}_{1} \mathrm{a}+\mathrm{b}_{2} \mathrm{R}^{*}\right)^{\mathrm{i}-1}$ and $1+\mathrm{R}^{*}+\mathrm{b}_{1} \mathrm{a}+\mathrm{b}_{2} \mathrm{R}^{*}$ are proportional. Differentiate $1+\mathrm{R}^{*}+\mathrm{b}_{1} \mathrm{a}+\mathrm{b}_{2} \mathrm{R}^{*}$ to $\mathrm{a}$ :

$\frac{d\left(1+R^{*}+b_{1} a+b_{2} R^{*}\right)}{d a}=b_{1}>0$ 
International Journal of Social Science and Economic Research

ISSN: $2455-8834$

Volume: 05, Issue: 02 "February 2020"

$1+R^{*}+b_{1} a+b_{2} R^{*}$ is proportional to $a$. When a takes the maximum value of $1,1+R^{*}+b_{1} a+b_{2} R^{*}$ takes the maximum value, and total profit also takes the maximum value. At this time, $R_{\text {net }}>0$ and $a>a^{*}$ are automatically satisfied.

In summary, if they are in a long-term mature market environment, microfinance institutions will not face the problem of dual goals. If the institution puts credit funds into poor customer groups, the total profit of each period will also reach the maximum. At this point, the dual goals no longer conflict, but are achieved simultaneously. Therefore, in the long-term and with a mature market environment, microfinance institutions can achieve the coordinated development of dual goals $^{[5] 6]}$.

\section{THE INHERENT CONFLICT OF DUAL GOALS —EMPIRICAL TEST}

\subsection{Sample selection and data source}

This paper conducts an empirical test on the conflict between the dual goals of microfinance institutions. The method used is the simultaneous equations analysis in econometrics, and the software used is Eviews 8.0. Based on the availability of data and the representativeness of the sample, this paper selects 39 non-governmental organizations and rural credit cooperatives (Such as Shandong Shanxian Limin Mutual Fund Cooperatives, Yunnan Jinping Autonomous County Rural Cooperative Development Promotion Association, etc.), 91 rural commercial banks (such as Jiangyan Rural Commercial Bank of Jiangsu, Hefei Technology Rural Commercial Bank, etc.), 8 loan companies (such as Jiangsu Suzhou Industrial Park Jinjihu Rural Microfinance Co., Ltd., Ningxia Huimin Microfinance Company, etc.) and 34 village banks (such as Beijing Huairou Rongxing Village Bank, Sichuan Yilong Huimin Village Bank, etc.) of China as samples. The total is 172. Since the establishment of microfinance institutions varies in length, the selected data year range is 2013-2018. The data sources are the annual report of China Microfinance Union, the annual report of institutions and the MIX website.

\subsection{Index selection and model design}

In this empirical study, the return on assets (ROA) is selected as a measure of business sustainable development goals. This is because some better indicators such as sustainability indicators (OSS, FSS) have more extensive and strict data requirements, but most domestic microfinance institutions have not disclosed the specific value of this indicator ${ }^{[7][8]}$. Therefore, based on the availability of data, this paper chose ROA to disclose the overall financial performance of the institution. With reference to the definition of ROA and the conclusions of previous studies, this paper selects the following indicators as the influencing factors of business sustainable development goals, as shown in Table 1. 
International Journal of Social Science and Economic Research

ISSN: $2455-8834$

Volume: 05, Issue: 02 "February 2020"

Table 1: Factors affecting business sustainable development goals

\begin{tabular}{|c|c|}
\hline \multicolumn{1}{|c|}{ Index } & Basic assumptions \\
\hline Total Assets (ASS) & Assuming ROA is positively related to it \\
\hline Credit staff average customers (BPS) & Assuming ROA is positively related to it \\
\hline Net profit (NP) & Assuming ROA is positively related to it \\
\hline Cost-to-income ratio (CIA) & Assume ROA is negatively related to it \\
\hline NPL ratio (NPL) & Assume ROA is negatively related to it \\
\hline
\end{tabular}

Many empirical studies have focused on the breadth and depth of financial services provided by institutions to the poor. Frequently used indicators include the number of active customers $(\mathrm{ABN})$, the average loan line / gross national income (ALZ), and the proportion of women customers (PWB).This paper selects ALZ as a measure of social poverty reduction goals. ABN represents the overall customer situation, not the poor customer group; PWB represents the proportion of women customers, does not represent the situation of all poor customers and it is not comprehensive and accurate; ALZ takes regional differences and economic development levels into consideration, and more comprehensively defines the poor groups of customers in different regions and under different economic conditions. With reference to the definition of ALZ, as well as the conclusions of previous studies and commonly used indicators, this paper selects the following indicators as the influencing factors of social poverty alleviation goals, as shown in Table 2.

Table 2: Factors affecting social poverty alleviation goals

\begin{tabular}{|c|c|}
\hline \multicolumn{1}{|c|}{ Index } & Basic assumptions \\
\hline Agriculture-related loan ratio (RLN) & Suppose ALZ is negatively related to it \\
\hline Active customers (ABN) & Suppose ALZ is negatively related to it \\
\hline Women's Customer Proportion (PWB) & Suppose ALZ is negatively related to it \\
\hline Total Assets (ASS) & Suppose ALZ is negatively related to it \\
\hline Average operating expenses per loan (EPL) & Assuming that ALZ is positively related to it \\
\hline
\end{tabular}




\section{International Journal of Social Science and Economic Research}

ISSN: $2455-8834$

Volume: 05, Issue: 02 "February 2020"

The explanatory variables on the left side of the simultaneous equation model set in this article are representative indicators of the dual objectives of microfinance institutions. These two representative indicators will also be on the right side of the other equation as one of the explanatory variables, and the remaining explanatory variables are the respective influencing factors of the dual goals. Simultaneous equation model is as follows:

$\left\{\mathrm{ROA}=\mathrm{c}_{1}+\alpha_{1} \mathrm{ALZ}+\alpha_{2} \mathrm{ASS}+\alpha_{3} \mathrm{BPS}+\alpha_{4} \mathrm{NP}+\alpha_{5} \mathrm{CIA}+\alpha_{6} \mathrm{NPL}+\mathrm{u}_{1}\right.$ $\mathrm{ALZ}=\mathrm{c}_{2}+\beta_{1} \mathrm{ROA}+\beta_{2} \mathrm{ASS}+\beta_{3} \mathrm{RLN}+\beta_{4} \mathrm{ABN}+\beta_{5} \mathrm{PWB}+\beta_{6} \mathrm{EPL}+\mathrm{u}_{2}$

\subsection{Correlation analysis}

As shown in Table 3, it is the correlation analysis of the main variables.

Table 3: Correlation analysis of the main variables

\begin{tabular}{|l|c|c|c|c|c|c|c|c|c|c|c|}
\hline & ROA & NPL & ALZ & PWB & ABN & CIA & ASS & RLN & EPL & BPS & NP \\
\hline ROA & 1 & -0.02 & 0.134 & -0.18 & -0.03 & -0.31 & 0.221 & -0.11 & 0.078 & 0.152 & 0.2399 \\
\hline NPL & -0.02 & 1 & -0.14 & -0.18 & 0.32 & 0.021 & 0.409 & -0.16 & 0.489 & -0.01 & -0.11 \\
\hline ALZ & 0.134 & -0.14 & 1 & 0.026 & -0.18 & -0.23 & 0.22 & 0.187 & -0.09 & 0.067 & 0.132 \\
\hline PWB & -0.18 & -0.18 & 0.026 & 1 & -0.23 & -0.04 & -0.12 & 0.767 & -0.14 & -0.09 & -0.21 \\
\hline ABN & -0.03 & 0.32 & -0.18 & -0.23 & 1 & 0.053 & 0.289 & -0.12 & 0.509 & -0.32 & -0.1 \\
\hline CIA & -0.31 & 0.021 & -0.23 & -0.04 & 0.053 & 1 & -0.11 & -0.08 & -0.03 & -0.12 & -0.09 \\
\hline ASS & 0.221 & 0.409 & 0.22 & -0.12 & 0.289 & -0.11 & 1 & -0.2 & 0.334 & 0.209 & 0.346 \\
\hline RLN & -0.11 & -0.16 & 0.187 & 0.767 & -0.12 & -0.08 & -0.2 & 1 & -0.18 & -0.20 & -0.22 \\
\hline EPL & 0.078 & 0.489 & -0.09 & -0.14 & 0.509 & -0.03 & 0.334 & -0.18 & 1 & 0.009 & 0.102 \\
\hline BPS & 0.152 & -0.01 & 0.067 & -0.09 & -0.32 & -0.12 & 0.209 & -0.20 & 0.009 & 1 & 0.289 \\
\hline NP & 0.2399 & -0.11 & 0.132 & -0.21 & -0.1 & -0.09 & 0.346 & -0.22 & 0.102 & 0.289 & 1 \\
\hline
\end{tabular}

According to the results in the table, the overall correlation between the indicators is not obvious, and the probability of multicollinearity in the model is small. Moreover, the correlation coefficient between ROA and ALZ is 0.134 , showing a weak positive correlation. 
International Journal of Social Science and Economic Research

ISSN: $2455-8834$

Volume: 05, Issue: 02 "February 2020"

\subsection{Single equation regression results}

Regression analysis is performed on the two single equations in the model using the least squares method, and the results are shown in Table 4.

Table 4: Single equation regression results

\begin{tabular}{|c|c|c|c|c|c|c|c|}
\hline \multicolumn{4}{|c|}{ Business sustainable development goal equation } & \multicolumn{4}{|c|}{ Social poverty alleviation goal equation } \\
\hline & Coefficient & $\begin{array}{l}\text { Standard } \\
\text { deviation }\end{array}$ & $\begin{array}{l}\text { t-value (p- } \\
\text { value) }\end{array}$ & & Coefficient & $\begin{array}{l}\text { Standard } \\
\text { deviation }\end{array}$ & $\mathrm{t}$-value (p-value) \\
\hline $\mathrm{c}(10)$ & 0.009232 & 0.034782 & $4.213(0.0028)$ & $\mathrm{c}(20)$ & 73.829 & 3.8911 & $3.9782(0.004021)$ \\
\hline $\mathrm{c}(11)$ & 0.0001827 & 0.000097 & $2.479(0.032)$ & $\mathrm{c}(21)$ & 10.32 & 32.892 & $1.9223(0.1008)$ \\
\hline$c(12)$ & $2.33 \mathrm{E}-7$ & 0.000008 & $1.332(0.212)$ & $c(22)$ & 0.0049 & 0.0006 & $3.021(0.0189)$ \\
\hline $\mathrm{c}(13)$ & -0.000315 & 0.00287 & $2.892(0.03078)$ & $\mathrm{c}(23)$ & -1.638 & 13.291 & $-2.421(0.0413)$ \\
\hline $\mathrm{c}(14)$ & $4.29 \mathrm{E}-6$ & 0.000398 & $3.029(0.0193)$ & $\mathrm{c}(24)$ & -0.009 & 0.0038 & $-2.931(0.0239)$ \\
\hline $\mathrm{c}(15)$ & $-3.98 \mathrm{E}-6$ & $2.965 \mathrm{E}-6$ & $\begin{array}{c}- \\
0.1321(0.4243)\end{array}$ & $\mathrm{c}(25)$ & -0.042 & 0.0006 & $-1.826(0.1789)$ \\
\hline $\mathrm{c}(16)$ & -0.00391 & 0.00026 & $3.382(0.00832)$ & $\mathrm{c}(26)$ & -5.391 & 1.3981 & $-3.192(0.00931)$ \\
\hline \multicolumn{2}{|c|}{ R-squared } & \multicolumn{2}{|c|}{0.5632} & \multicolumn{2}{|c|}{ R-squared } & \multicolumn{2}{|c|}{0.4721} \\
\hline \multicolumn{2}{|c|}{$\begin{array}{c}\text { Durbin-Watson } \\
\text { stat }\end{array}$} & \multicolumn{2}{|c|}{2.08736} & \multicolumn{2}{|c|}{$\begin{array}{c}\text { Durbin-Watson } \\
\text { stat }\end{array}$} & \multicolumn{2}{|c|}{1.9021} \\
\hline
\end{tabular}

According to the above regression results, the goodness of fit $\mathrm{R}^{2}$ of the two single equations are 0.5632 and 0.4721 , which are low; And the partial coefficient $\mathrm{p}$ value is greater than 0.05 , failing to pass the $t$ test with a significance level of $5 \%$, and the overall regression result is not very satisfactory.

\subsection{Simultaneous equation estimation results}

The two single equations in the simultaneous equation model set in this paper are over-identified, so the simultaneous equations can be solved. This paper uses a three-stage least squares method 
International Journal of Social Science and Economic Research

ISSN: $2455-8834$

Volume: 05, Issue: 02 "February 2020"

to perform regression analysis on the model, and the results are shown in Table 5.

Table 5: Simultaneous equation estimation results

\begin{tabular}{|c|c|c|c|c|c|c|c|}
\hline \multicolumn{4}{|c|}{ Business sustainable development goal equation } & \multicolumn{4}{|c|}{ Social poverty alleviation goal equation } \\
\hline & Coefficient & $\begin{array}{l}\text { Standard } \\
\text { deviation }\end{array}$ & $\begin{array}{c}\text { t-value (p- } \\
\text { value) }\end{array}$ & & Coefficient & $\begin{array}{l}\text { Standard } \\
\text { deviation }\end{array}$ & t-value (p-value) \\
\hline $\mathrm{c}(10)$ & 0.13829 & 0.04729 & $4.4321(0.00132)$ & $\mathrm{c}(20)$ & 39.311 & 4.3211 & $3.336(0.00832)$ \\
\hline $\mathrm{c}(11)$ & 0.0002001 & 0.00032 & $-2.892(0.03192)$ & $\mathrm{c}(21)$ & 63.312 & 42.82 & $-2.462(0.0398)$ \\
\hline $\mathrm{c}(12)$ & $1.98 \mathrm{E}-7$ & $3.21 \mathrm{E}-7$ & $2.432(0.0402)$ & $\mathrm{c}(22)$ & -0.00252 & 0.0003 & $-2.588(0.0393)$ \\
\hline $\mathrm{c}(13)$ & 0.000124 & 0.00038 & $3.021(0.0231)$ & $\mathrm{c}(23)$ & -12.32 & 9.21 & $-2.21(0.0494)$ \\
\hline$c(14)$ & $3.92 \mathrm{E}-6$ & $1.09 \mathrm{E}-6$ & $3.133(0.014)$ & $c(24)$ & -0.0052 & 0.0001 & $-3.088(0.022)$ \\
\hline $\mathrm{c}(15)$ & $-1.43 \mathrm{E}-5$ & $1.49 \mathrm{E}-5$ & $-2.23(0.0489)$ & $c(25)$ & -0.0021 & 0.0003 & $-2.98(0.0287)$ \\
\hline $\mathrm{c}(16)$ & -0.0052 & 0.00011 & $-2.78(0.0389)$ & $\mathrm{c}(26)$ & 1.23 & 0.9211 & $3.23(0.00997)$ \\
\hline \multicolumn{2}{|c|}{ R-squared } & \multicolumn{2}{|c|}{0.7024} & \multicolumn{2}{|c|}{ R-squared } & \multicolumn{2}{|c|}{0.6532} \\
\hline \multicolumn{2}{|c|}{$\begin{array}{c}\text { Durbin-Watson } \\
\text { stat }\end{array}$} & \multicolumn{2}{|c|}{1.9921} & \multicolumn{2}{|c|}{$\begin{array}{c}\text { Durbin-Watson } \\
\text { stat }\end{array}$} & \multicolumn{2}{|c|}{2.1263} \\
\hline
\end{tabular}

According to the above regression results, the goodness of fit R2 of the two equations in the simultaneous equations are 0.7024 and 0.6532 respectively, which is significantly improved over the results of the single equation regression analysis. This is because the simultaneous equation model involves information for the entire system. And the p-values of all coefficients are less than 0.05 . The t-test with a significance level of $5 \%$ is passed and some even pass the t-test with a significance level of $1 \%$. The overall regression effect is ideal. The DW value is close to 2 , which indicates that the model does not have the problem of autocorrelation.

\subsection{Analysis of empirical results}

In the single-equation regression analysis, the social poverty alleviation index in the business sustainable development goal equation passed the $t$ test with a significance level of $5 \%$, while the business sustainable development index in the social poverty alleviation target equation failed the significance test; However, in the simultaneous equations, both of them passed the significance test. This is because the simultaneous equations use the information of the entire 
International Journal of Social Science and Economic Research

ISSN: $2455-8834$

Volume: 05, Issue: 02 "February 2020"

model system and fully consider the relationship between the mutual influence of the dual goals. This mutual influence is more significant in empirical tests.

In the simultaneous equations, the ALZ coefficient in the business sustainable development goal equation is 0.0002001 , and the ROA coefficient in the social poverty reduction goal equation is 63.312, both of which are positive values, indicating that there is a positive correlation between ROA and ALZ, which is consistent with the results of the correlation analysis. The larger the ROA, the higher the degree of achievement of commercial sustainable development goals; the lower the ALZ, the higher the degree of achievement of social poverty reduction goals. Therefore, according to the regression results of simultaneous equations, there is a negative correlation between the business sustainable development goals and social poverty reduction goals of microfinance institutions, and there is a certain conflict between the dual goals.

In simultaneous equations, basically every variable passed the significance test; In the business sustainable development objective equation, the coefficients of total assets, average number of credit personnel, and net profit in the influencing factors are all positive, and the coefficients of cost-income ratio and non-performing loan ratio are all negative. It indicates that the larger the institution, the better the profitability, the higher the security, and the better its sustainable business development. In the social poverty alleviation target equation, the coefficients of the total assets, the proportion of agricultural loans, the number of active customers, and the percentage of women customers in the influencing factors are all negative, and the coefficient of the average operating cost of each loan is positive, which is also consistent with the basic assumptions. It shows that the more the organization serves the poor customer groups, the higher the operating efficiency, the stronger the service capacity, and the better its social poverty alleviation performance.

\section{CONCLUSION}

This paper analyzes the relationship between the sustainable development goals and social poverty reduction goals of microfinance institutions from the perspective of theory and empirical analysis. The theoretical analysis shows that from a short-term static perspective, there is a certain conflict between dual goals, and the pursuit of one goal will sacrifice the other goal to a certain extent; From the perspective of long-term dynamics, the dual goals also have the possibility of mutual equilibrium and coordination, and if the market develops maturely, the dual goals can be achieved simultaneously without conflict. The empirical analysis is a regression analysis of the data of 172 microfinance institutions in China using the simultaneous equation model analysis; The conclusion shows that there is a negative correlation between the dual goals of microfinance institutions and there is a certain conflict; The larger the institution, the better the profitability and the higher the security, the better the sustainable business development; The 
International Journal of Social Science and Economic Research

ISSN: $2455-8834$

Volume: 05, Issue: 02 "February 2020"

more an organization serves poor customer groups, the higher its operational efficiency, the stronger its service capabilities, and the better its performance in helping the poor.Based on this, this article puts forward corresponding policy recommendations, hoping to play a certain role in achieving the coordinated development of dual goals for microfinance institutions, the construction of an inclusive financial system, improving people's livelihood, and promoting economic development.

For MFIs: (1) Expansion of funding sources and expansion of business scale ${ }^{[9]}$; (2) Innovate product mechanisms to reduce costs and risks; (3) Make good use of advantages; (4) Determine reasonable interest rates to achieve financial sustainability; (5) Strengthen risk control; (6) Focus on institutional innovation ${ }^{[10]}$.

For the government: (1) Create a good financial environment; (2) Adhere to favorable policies such as the risk compensation system; (3) Improve the legal system and supervision mechanism; (4) Accelerate the construction of financial infrastructure.

\section{ACKNOWLEDGEMENTS}

I am very grateful to my mentor, Professor Qiang Xu , who provided me with a lot of help and guidance in the process of writing my dissertation, especially in mathematical modeling and software applications. At the same time, I am very grateful to my family and classmates for their wholehearted support in writing my thesis.

\section{REFERENCES}

[1] Lee, J.H. and H.O. Choi. Stakeholders' views on reducing financial support in government-led ecotourism areas[J]. Ocean \& Coastal Managemen.2017, 144: 7-15.

[2] Christen, P. ,R. Rosenberg, and V. Jayadeva. Financial Institutions with a "Double Bottom Line": Implications for the Future of Microfinance [R] CGAP Occasional Paper, 2004, 07.

[3] Mc Intosh, C., G. Villaran, and B. Wydick. Microfinance and Home Improvement: Using Retrospective Panel Data to Measure Program Effects on Fundamental Events [J].World Development, 2011, 39(6): 922-937.

[4] Frank, C,2008. Stemming the Tide of Mission Drift: Microfinance Transformations and the Double Bottom Line, [M]. Focus Note, April 17, 2008, Women's World Banking.

[5] Schreiner, M. Does Microcredit Really Help Poor People? [J].CGAP Focus Note, 59, January, 2010. 
[6] Zeller, M. and R. L. Meyer. The Triangle of Microfinance: Financial Sustainability, Outreach, and Impact $[\mathrm{M}]$. Baltimore and London: Johns Hopkins University Press, 2002.

[7] Thapa G. Sustainability and Governance of Microfinance Institutions: Recent Experiences and Some Lessons for Southeast Asia [J]. Asian Journal of Agriculture and Development, 2007, (1): 65-73.

[8] Rosenberg R. Measuring Results of Microfinance Institutions Minimum: Indicators that Donors and Investors Should Track [J]. A Technical Guide, 2009,(1).

[9] Olevares-Polanco, F. Commercializing Microfinance and Deepening Outreach? [J]. Journal of Microfinance, 2005, 7(2): 47-69.

[10] Perrault, E.K.C.S. Sustainability in the University Student's Mind: Are University Endorsements, Financial Support, and Programs Making a Difference?[J]. Journal of Geoscience Education. 2017, 65 (2): 194-202. 